\title{
Determination of maternal risk factors of preterm delivery: adjusted for sparse data bias; results from a population-based case-control study in Iran
}

\author{
Mehrdad Valipour, PhDc ${ }^{1,2}$, Erfan Ayubi, PhD ${ }^{3}$, Narges Shiravand, B.S ${ }^{2}$, Yousef Moradi, PhDc ${ }^{4}$, \\ Abolfazl Abbaszadeh, PhD ${ }^{5}$, Firooz Amrai, PhDc ${ }^{6}$, Shahin Mokhtari, B.S², Kaveh Bahmanpour, PhD ${ }^{7}$ \\ Kamyar Mansori, PhD $^{8}$
}

\begin{abstract}
'Department of Epidemiology, School of Public Health, Iran University of Medical Sciences, Tehran; ${ }^{2}$ Department of Communicable Disease Control and Prevention, Deputy of Health, Lorestan University of Medical Sciences, Khorramabad; ${ }^{3}$ Department of Community Medicine, School of Medicine, Zahedan University of Medical Sciences, Zahedan; ${ }^{4}$ Department of Epidemiology, School of Public Health, Iran University of Medical Sciences, Tehran; ${ }^{5}$ Lorestan University of Medical Sciences, Khorramabad; ${ }^{6}$ South Tehran Branch, Islamic Azad University, Tehran; ${ }^{7}$ Department of Nursing and Midwifery, Sanandaj Branch, Islamic Azad University, Sanandaj; ${ }^{8}$ Department of Biostatistics and Epidemiology, School of Medicine, Zanjan University of Medical Sciences, Zanjan, Iran
\end{abstract}

Objective

To determine the maternal risk factors associated with preterm delivery in Iran.

Methods

A population-based case-control study was conducted including 48 women having preterm delivery (case group) and 100 women having term delivery (control group) between March 2007 and March 2012 in the maternity hospitals of the Selseleh County, Lorestan province, Iran. Information regarding maternal risk factors was collected by structured interview and reviewing the medical records. The maternal risk factors associated with preterm delivery were identified using univariate and multivariable logistic regression analysis after adjusting the sparse data bias. The area under the receiver operating characteristic $(R O C)$ curves was estimated to evaluate the discrimination power of the statistical models.

Results

Multivariable analysis demonstrated that multiparty (odds ratio [OR], 14.23; 95\% confidence interval [Cl], 1.60-127.05), history of gestational diabetes $(\mathrm{OR}, 0.10 ; 95 \% \mathrm{Cl}, 0.01-0.99)$, thyroid dysfunction (OR, 97.32; 95\% Cl, 5.78-1,637.80), urinary tract infection $(\mathrm{OR}, 16.60 ; 95 \% \mathrm{Cl}, 3.20-85.92)$, and taking care during pregnancy $(\mathrm{OR}, 0.12 ; 95 \% \mathrm{Cl}, 0.03-0.50)$ had significant impact on preterm delivery after adjusting the potential confounders. The area under the ROC curve for the aforementioned maternal risk factors was $0.86(95 \% \mathrm{Cl}, 0.80-0.92)$.

\section{Conclusion}

Our study provides evidence for the associations between multiparty, history of gestational diabetes, thyroid dysfunction, urinary tract infection, as well as taking care during pregnancy, and preterm delivery.

Keywords: Pregnancy; Risk factors; Premature delivery; Case-control studies; Iran

\section{Introduction}

Preterm delivery takes place before the 37 th week of pregnancy [1]. This type of delivery is one of the most important causes of mortality and morbidity in infants around the world $[2,3]$. Even, in the most developed countries, the preterm delivery rate has increased. For example, in the United States,

Received: 2019.04.25. Revised: 2019.06.16. Accepted: 2019.07.16. Corresponding author: Kamyar Mansori, $\mathrm{PhD}$

Department of Biostatistics and Epidemiology, School of Medicine, Zanjan University of Medical Sciences, Zanjan, Iran E-mail: kamyarmansori@yahoo.com https://orcid.org/0000-0003-3527-4741

Articles published in Obstet Gynecol Sci are open-access, distributed under the terms of the Creative Commons Attribution Non-Commercial License (http://creativecommons. org/licenses/by-nc/3.0/) which permits unrestricted non-commercial use, distribution, and reproduction in any medium, provided the original work is properly cited.

Copyright $\odot 2020$ Korean Society of Obstetrics and Gynecology 


\title{
Obstetrics \& Gynecology Science
}

\author{
Vol. 63, No. 2, 2020
}

it has risen from $9.5 \%$ in 1981 to $12.7 \%$ in 2005 [4]. In Europe and other developed countries, the estimated preterm delivery rate is about $5-9 \%[5,6]$. Preterm delivery is also responsible for $17-34 \%$ of deaths in infants in the first year of life in the United States [7]. However, almost $90 \%$ of the preterm deliveries occur in the developing countries of which $85 \%$ take place in Asia and Africa [8]. In Iran, as a developing country, the preterm delivery rate was estimated between $5.6 \%$ and $13.4 \%$ based on the geographical regions under study [9]. Preterm birth causes $75 \%$ of perinatal deaths and over $50 \%$ of the preterm babies have long-term morbidities. Many preterm infants are at increased risk of death, different diseases, and disabilities, such as developmental disorders of the nervous and respiratory system, defect in sense, learning disability, digestive complications, and many other health problems $[10,11]$.

Given the worrying trend of preterm delivery throughout the world and its related outcomes, it seems that studying the causes and risks of these factors is very important $[8,12]$. Factors causing preterm birth have not been fully identified yet, however, various studies have considered different factors in the etiology of this outcome [13]. Some studies in this regard have mentioned the following factors as possible causes of preterm birth: genetic factors, rupture of membranes, hypertension, diabetes, multiparity, multiple births, techniques of infertility treatment, elective Caesarean section during previous pregnancies, smoking and alcohol consumption during pregnancy, mental disorders, and environmental exposures [8]. However, identifying the precise cause of preterm delivery still requires further studies, especially in developing countries where few studies have been conducted in this area [14].

Hence, given the importance of preterm delivery and its consequences as a major global health problem and the few studies conducted so far in Iran, the present study was designed to determine the maternal risk factors of preterm delivery in Iran. Identifying the risk factors can be an effective step in preventing and controlling the consequences and complications of preterm delivery.

\section{Materials and methods}

\section{Study design and subjects}

This study was a population-based case-control study. Cases included all pregnant mothers referred to the maternity wards of the Selseleh County hospitals (Lorestan province, Iran) who had preterm delivery between March 21, 2007 and March 21, 2012. The preterm delivery was defined as delivery before 37 weeks of gestation. Preterm delivery cases were identified by daily monitoring of all the new deliveries in all the maternity wards of the County hospitals. On the other hands, the preterm delivery cases were considered as incident cases. Then, for each case, two controls were selected. The controls were a selected by random sampling from all the pregnant mothers referred to the same maternity wards of the County hospitals who had term delivery ( $\geq 37$ weeks of gestation) during the same period ( \pm 2 weeks). In this study, mothers with premature infants due to congenital or chromosomal anomalies were excluded.

\section{Data collection}

The data collection tool was a standard questionnaire. However, some information was obtained through interviews with the pregnant mothers and some were gathered from the medical records. The questionnaire included information, such as demographic characteristics of the mother (age, occupation, body mass index, education, etc.), past obstetric history (gestational age at delivery, history of caesarian delivery, unwanted pregnancy, gravidity, multiparity, childbirth, etc.), complications of pregnancy and delivery (such as history of gestational diabetes, hypertension, abortion, eclampsia, placenta previa, uterine prolapse, stillbirth and etc.). The data were collected by a trained research doctor.

\section{Statistical analysis}

For analysis, the relevant data were entered into Stata 14. Descriptive analyses, such as mean and standard deviation were used for the continuous variables; and number and relative frequency were used for the categorical variables. For determination of the most important risk factors of preterm delivery, univariate and multivariable logistic regression analyses were performed. Then, the crude and adjusted odds ratio (OR) with 95\% confidence interval (CI) were calculated. A large number of risk factors were evaluated, and hence, inadequate data for the combination of the maternal risk factors and preterm delivery ( $2 \times 2$ contingency table) are expected. It is argued that when there are inadequate data for the combination of the risk factors and outcomes, the estimates, such as $\mathrm{OR}$ and its $\mathrm{Cl}$, could be biased [15]. As a result, the 


\section{Obstetrics \& Gynecology Science}

Mehrdad Valipour, et al. Risk factors of preterm delivery

OR tends to be inflated and its $\mathrm{Cl}$ tends to be inappropriately wide. Such bias is known as sparse data bias and it can exaggerate the results of the multivariable analysis [15]. Penalization via data augmentation and firth bias adjustment was performed to offset the impact of sparse data bias on the results. Firth bias adjustment is a common traditional technique for reducing sparse data bias in which $1 / 2$ is added to each cell of a contingency table. In penalization by data augmentation method, a very weakly informative prior $[\log -\mathrm{F}(2$, 2)] was considered for the effect of the maternal risk factors ( $\beta i$ in logistic regression model or ORs) on the preterm delivery. It is argued that very weakly informative prior provides a plausible range for the relative estimates with $95 \%$ certainty and the OR of the effect of maternal risk factors on preterm delivery falls between 1/40 and 40 [16]. The area under the receiver operating characteristic (ROC) curve was used for assessing the discriminative ability of the multivariable logistic regression analysis. A $P$-value of $<0.05$ was considered as statistically significant.

\section{Results}

The maternal characteristics of the cases and controls, as well as the results of the univariate logistic regression analysis, are shown in Table 1. A total of 48 cases with preterm delivery and 100 controls were enrolled in the study. The mean (standard deviation) age of the cases was 32.25 (6.81) years and that of the controls was $29.33(6.56)$ years $(P=0.02)$. A majority of the cases and controls had a school or lower level of education ( $65 \%$ vs. $70 \%$, respectively). A majority of the cases and controls had a gravida of $\leq 3$, history of $\leq 2$ childbirths, and no history of abortion.

A significant difference was found between the cases and the controls regarding the multiparty, history of coronary heart disease (CHD), gestational diabetes, blood pressure, thyroid dysfunction, hemorrhage, urinary tract infection, taking care during pregnancy, and FBS level (all $P \leq 0.05$ ). The highest significant crude OR was found for multiparity (OR, 31.60; $95 \% \mathrm{Cl}, 3.99-250.09$ ). The odds of preterm delivery was 5.40 times higher in those having a history of urinary tract infection than those without $(95 \% \mathrm{Cl}, 2.24-12.97)$. Similarly, the odds of the outcome was 2.73 times lower in the women who received $\geq 6$ care during pregnancy from rural or urban health centers than those who received $<6$ care during pregnancy $(\mathrm{OR}, 0.37 ; 95 \% \mathrm{Cl}, 0.15-0.88)$.

The results of the multivariable logistic regression analysis are presented in Table 2. After selecting the variables with a $P$-value of $\leq 0.20$ in the univariate analysis for the multivariable analysis, only multiparity, history of gestational diabetes, thyroid dysfunction, urinary tract infection, and taking care during pregnancy were statistically significant $(P \leq 0.05)$. The highest adjusted OR was determined for a history of thyroid dysfunction (OR, 97.32; 95\% Cl, 5.78-1,637.80).

The ROC curves for model 1 with all 13 maternal characteristics included in the multivariable logistic regression analysis and for model 2 with only the significant maternal characteristics included in the multivariable logistic regression analysis are shown in Fig. 1. In analyses that compared the ability of the models to discriminate preterm labor, the ROC for model 1 was significantly greater than that of model 2 ( 0.93 vs. 0.86 , $P=0.002$ ).

\section{Discussion}

The present study aimed to determine the maternal risk factors for preterm delivery in Iran, which was achieved by a population-based case-control study. The results of the multivariable logistic regression analysis showed that variables, such as multiparity, history of gestational diabetes, thyroid dysfunction, urinary tract infection, and taking care during pregnancy had significant statistical associations with preterm delivery $(P<0.05)$. Besides, the area under the ROC curve for the significant maternal variables in the multivariable logistic regression analysis was $0.86(95 \% \mathrm{Cl}, 0.80-0.92)$

In the present study, mothers who received prenatal care for $\geq 6$ times during pregnancy had a lower risk of preterm delivery as compared to those who received care for $<6$ times (OR, 0.12; 95\% Cl, 0.03-0.50). This finding has been supported by various other studies in this regard [13,14,17-19]. For example, the study by Jiang et al. [13] showed that lack of prenatal care is related to an increased risk of preterm birth, so that the mothers without prenatal care during pregnancy had 5.19 times increased risk of preterm birth (OR, 5.19; $95 \% \mathrm{Cl}, 3.77,-7.14)$; and mothers with irregular prenatal care had 2.87 times of increased risk of preterm birth (OR, 2.87; 95\% Cl, 2.16-3.80). Another study performed in Iran showed that mothers of premature infants received less perinatal care; while with more care, the risk of premature 


\section{Obstetrics \& Gynecology Science}

Vol. 63, No. 2, 2020

Table 1. Association between preterm delivery and maternal characteristics using univariate logistic regression analysis

\begin{tabular}{|c|c|c|c|c|}
\hline Characteristics & Case $(n=48)$ & Control $(n=100)$ & OR $(95 \% \mathrm{Cl})$ & $P$-value \\
\hline Age (yr) & $32.25(6.81)$ & $29.33(6.56)$ & $1.06(1.01-1.12)$ & 0.02 \\
\hline \multicolumn{5}{|l|}{ Mother's education } \\
\hline Illiterate & $2(5)$ & $14(14)$ & - & \\
\hline Primary school & $6(15)$ & $8(8)$ & $4.43(0.82-23.95)$ & 0.08 \\
\hline Middle school & $10(25)$ & $12(12)$ & $4.87(1.01-23.49)$ & 0.05 \\
\hline High school & $8(20)$ & $36(36)$ & $1.35(0.29-6.27)$ & 0.70 \\
\hline Associate's degree ${ }^{a)}$ & 0 & $12(12)$ & $0.23(0.01-5.30)$ & 0.36 \\
\hline Bachelor's degree & $12(30)$ & $16(16)$ & $4.39(0.95-20.29)$ & 0.05 \\
\hline Master's degree and over & $2(5)$ & $2(2)$ & $5.79(0.63-52.78)$ & 0.11 \\
\hline \multicolumn{5}{|l|}{ Husband's education } \\
\hline Illiterate & $6(13.64)$ & $16(16.33)$ & - & \\
\hline Primary school & $4(9.09)$ & $2(2.04)$ & $5.33(0.76-37.09)$ & 0.09 \\
\hline Middle school & $6(13.64)$ & $6(6.12)$ & $2.66(0.61-11.59)$ & 0.19 \\
\hline High school & $6(13.64)$ & 34 (34.69) & $0.47(0.13-1.68)$ & 0.24 \\
\hline Associate's degree & $10(22.73)$ & $10(10.20)$ & $2.66(0.73-9.62)$ & 0.13 \\
\hline Bachelor's degree & $8(18.18)$ & $22(22.45)$ & $0.96(0.28-3.34)$ & 0.96 \\
\hline Master's degree and over & $4(9.09)$ & $8(8.16)$ & $1.33(0.29-6.11)$ & 0.71 \\
\hline \multicolumn{5}{|l|}{ Occupation } \\
\hline Unemployed & $42(87.50)$ & $78(78)$ & & 0.17 \\
\hline Employed & $6(12.50)$ & $22(22)$ & $0.50(0.19-1.34)$ & \\
\hline \multicolumn{5}{|l|}{ Gravidity } \\
\hline$\leq 3$ & $42(87.50)$ & $91(91)$ & - & 0.51 \\
\hline$>3$ & $6(12.50)$ & $9(9)$ & $1.44(0.48-4.32)$ & \\
\hline \multicolumn{5}{|l|}{ Childbirth } \\
\hline$\leq 2$ & $46(95.83)$ & $91(91)$ & - & 0.30 \\
\hline$>2$ & $2(4.17)$ & $9(9)$ & $0.43(0.09-2.11)$ & \\
\hline \multicolumn{5}{|l|}{ Abortion } \\
\hline 0 & $44(91.67)$ & $91(91)$ & - & 0.89 \\
\hline$\geq 1$ & $4(8.33$ & $9(9)$ & $0.91(0.26-3.14)$ & \\
\hline BMl & $24.95(3.86)$ & $25.74(4.51)$ & $0.95(0.88-1.03)$ & 0.30 \\
\hline \multicolumn{5}{|l|}{ Multiparity } \\
\hline No & $36(75)$ & 100 & - & 0.001 \\
\hline Yes & $12(25)$ & 0 & 31.60 (3.99-250.09) & \\
\hline \multicolumn{5}{|l|}{ Unwanted pregnancy } \\
\hline No & $38(79.17)$ & $84(84)$ & - & 0.47 \\
\hline Yes & $10(20.83)$ & $16(16)$ & $1.38(0.57-3.32)$ & \\
\hline \multicolumn{5}{|l|}{ History of preterm delivery ${ }^{a)}$} \\
\hline No & $48(100)$ & $94(94)$ & - & 0.20 \\
\hline Yes & 0 & $6(6)$ & $0.15(0.008-2.71)$ & \\
\hline \multicolumn{5}{|l|}{ History of stillbirth ${ }^{b)}$} \\
\hline No & $46(95.83)$ & 100 & - & 0.21 \\
\hline Yes & $2(4.17)$ & 0 & $4.53(0.45-45.36)$ & \\
\hline
\end{tabular}




\section{Obstetrics \& Gynecology Science}

Mehrdad Valipour, et al. Risk factors of preterm delivery

Table 1. Continued

\begin{tabular}{|c|c|c|c|c|}
\hline Characteristics & Case $(n=48)$ & Control $(n=100)$ & OR $(95 \% \mathrm{Cl})$ & $P$-value \\
\hline \multicolumn{5}{|l|}{ History of $\mathrm{CHD}^{\mathrm{b})}$} \\
\hline No & $44(91.67)$ & 100 & - & 0.05 \\
\hline Yes & $4(8.33)$ & 0 & $8.88(1.003-78.72)$ & \\
\hline \multicolumn{5}{|l|}{ History of caesarian } \\
\hline No & $48(100)$ & $96(96)$ & - & 0.31 \\
\hline Yes & 0 & $4(4)$ & $0.22(0.01-4.19)$ & \\
\hline \multicolumn{5}{|l|}{ History of gestational diabetes ${ }^{a}$} \\
\hline No & $48(100)$ & $84(84)$ & - & 0.04 \\
\hline Yes & 0 & $16(16)$ & $0.05(0.003-0.90)$ & \\
\hline \multicolumn{5}{|l|}{ History of blood pressure ${ }^{b)}$} \\
\hline No & $44(91.67)$ & 100 & - & 0.05 \\
\hline Yes & $4(8.33)$ & 0 & $8.88(1.003-78.72)$ & \\
\hline \multicolumn{5}{|l|}{ History of thyroid dysfunction } \\
\hline No & $38(79.17)$ & $98(98)$ & - & 0.001 \\
\hline Yes & $10(20.83)$ & $2(2)$ & $12.90(2.69-61.59)$ & \\
\hline \multicolumn{5}{|l|}{ History of hemorrhage ${ }^{b)}$} \\
\hline No & $44(91.67)$ & 100 & - & 0.05 \\
\hline Yes & $4(8.33)$ & 0 & $8.88(1.003-78.72)$ & \\
\hline \multicolumn{5}{|l|}{ History of urinary tract infection } \\
\hline No & $30(62.50)$ & $90(90)$ & - & $<0.001$ \\
\hline Yes & $18(37.50)$ & $10(10)$ & $5.40(2.24-12.97)$ & \\
\hline \multicolumn{5}{|l|}{ Taking care during pregnancy } \\
\hline$\leq 6$ & $40(83.33)$ & $65(65)$ & - & 0.02 \\
\hline$>6$ & $8(16.67)$ & $35(35)$ & $0.37(0.15-0.88)$ & \\
\hline Hemoglobin during pregnancy & $12.96(1.43)$ & $13.24(1.42)$ & $0.87(0.67-1.12)$ & 0.30 \\
\hline Hematocrit during pregnancy & $39.58(3)$ & $38.55(3.38)$ & $0.90(0.80-1.01)$ & 0.07 \\
\hline FBS during pregnancy & $83.97(16.97)$ & $78.33(12.45)$ & $1.02(1.004-1.05)$ & 0.04 \\
\hline BUN & $17.42(4.57)$ & $18.30(5.07)$ & $0.96(0.90-1.04)$ & 0.35 \\
\hline Creatinine & $0.69(0.19)$ & $0.68(0.15)$ & $1.37(0.14-12.76)$ & 0.78 \\
\hline
\end{tabular}

OR, odds ratio; Cl, confidence interval; BMI, body mass index; CHD, coronary heart disease; FBS, fasting blood sugar; BUN, blood urea nitrogen. $P$-values $\leq 0.20$ are bold.

${ }^{\text {a) }}$ Estimated using firth bias adjustment; ${ }^{\text {b) } E s t i m a t e d ~ u s i n g ~ p e n a l i z a t i o n ~ v i a ~ d a t a ~ a u g m e n t a t i o n ~ w i t h ~ l o g f ~}(2,2)$.

delivery was reduced [18]. Perhaps more attention to risk symptoms is paid during prenatal care along with appropriate health and treatment advice by the health care personnel. Hence, improving prenatal care and increasing the number of care can be effective in reducing the risk of premature birth. However, this interpretation about the number of prenatal care in the present study should be done with caution, because the low number of perinatal care in the mothers with premature infants might be due to premature birth and consequently shorter gestational age.

In agreement with other previous studies, the results of this study showed that there was a significant statistical association between multiparity and preterm delivery after adjusting the confounding variables $(\mathrm{OR}, 14.23 ; 95 \% \mathrm{Cl}, 1.60-127.05)$ $[13,20-23]$. The study by Shoja et al. [23] indicated that the odds of preterm delivery in mothers with multiparity preg- 


\title{
Obstetrics \& Gynecology Science
}

\author{
Vol. 63 , No. 2, 2020
}

Table 2. Association between preterm delivery and maternal risk factor using multivariable logistic regression analysis

\begin{tabular}{|c|c|c|}
\hline Characteristics & OR $(95 \% \mathrm{Cl})$ & $P$-value \\
\hline Age (yr) & $0.95(0.87-1.05)$ & 0.37 \\
\hline Occupation & $0.18(0.02-1.52)$ & 0.12 \\
\hline Multiparity & $14.23(1.60-127.05)$ & 0.02 \\
\hline History of preterm delivery ${ }^{a)}$ & $0.21(0.02-1.90)$ & 0.17 \\
\hline History of $\mathrm{CHD}^{\mathrm{a})}$ & $1.17(0.08-16.21)$ & 0.90 \\
\hline History of gestational diabetes ${ }^{\mathrm{a})}$ & $0.10(0.01-0.99)$ & 0.049 \\
\hline History of blood pressure ${ }^{a)}$ & $3.99(0.38-41.27)$ & 0.24 \\
\hline History of thyroid dysfunction ${ }^{a}$ & $97.32(5.78-1,637.80)$ & 0.001 \\
\hline History of hemorrhage ${ }^{a)}$ & $4.16(0.40-42.87)$ & 0.23 \\
\hline History of urinary tract infection & $16.60(3.20-85.92)$ & 0.001 \\
\hline Taking care during pregnancy & $0.12(0.03-0.50)$ & 0.004 \\
\hline Hematocrit during pregnancy & $0.90(0.77-1.06)$ & 0.23 \\
\hline FBS during pregnancy & $1.02(0.98-1.06)$ & 0.21 \\
\hline
\end{tabular}

$\mathrm{OR}$, odds ratio; $\mathrm{Cl}$, confidence interval; $\mathrm{CHD}$, coronary heart disease; FBS, fasting blood sugar. $P$-values $<0.05$ are bold.

${ }^{a}$ Estimated using penalization via data augmentation with $\log f(2,2)$.

nancy was more than those without multiparity pregnancy (OR, 3.09; 95\% Cl, 1.01-9.6). This problem may be because multiparity limits the uterine space for the fetus and also causes secretion of hormones inducing delivery, and therefore, preterm labor was more in this group.

In this study, we found a significant negative association between preterm delivery and maternal medical disorders, such as gestational diabetes $(\mathrm{OR}, 0.10 ; 95 \% \mathrm{Cl}, 0.01-1.01)$ after adjustment of the confounding variables. This finding was inconsistent with studies conducted in this field $[3,14,18,24-27]$. The study by Namakin et al. [18] in Iran showed that mothers with a history of gestational diabetes and hypertension had a higher risk of preterm delivery (OR, 2.99; 95\% Cl, 1.6-5.5). Zhang et al. [14] in China reported that women with a history of gestational diabetes have 3.44-fold increased risk of preterm birth (OR, 3.44; $95 \% \mathrm{Cl}$, 1.69-6.99). On the other hand, several studies have shown that there no association between preterm delivery and gestational diabetes $[13,28,29]$. For example, a case-control study in China showed no relationship between gestational diabetes and preterm delivery [13]. Perhaps one of the reasons for the negative relationship in this study was the low sample size involved. However, it can be said that gestational diabetes can affect the growth and development of the fetus

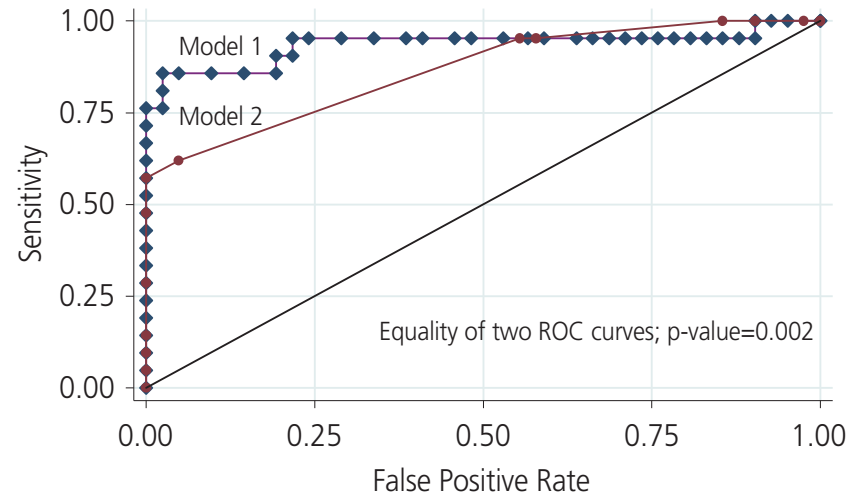

ROC area from model $1(95 \% \mathrm{CI}): 0.93(0.87,0.99)$ $\mathrm{ROC}$ area from model $2(95 \% \mathrm{Cl}): 0.86(0.80,0.92)$

Fig. 1. Receiver operating characteristic (ROC) curves of model 1 (all variables in the multivariable analysis) and model 2 (significant variables in the multivariable analysis). $\mathrm{Cl}$, confidence interval.

during pregnancy. Particularly, during the second and third trimesters of pregnancy, maternal diabetes can lead to a high level of nutrition and fetal growth. Subsequently, a large fetus with increased bodyweight may also increase the risk of preterm delivery. Therefore, regular monitoring of blood glucose during pregnancy should be given special attention.

In the present study, there was a significant statistical association between thyroid dysfunction $(\mathrm{OR}, 97.32 ; 95 \% \mathrm{Cl}$, $5.78-1,637.80)$ and preterm delivery in the multivariable logistic regression analysis, and this is in agreement with other previous studies [3,30-34]. A review by Nazarpour et al. [32] showed that thyroid dysfunction has adverse effects on pregnancy outcomes especially on the preterm delivery. Another review by Stagnaro-Green [30] also suggested that hypothyroidism and autoimmune thyroid disease are associated with preterm delivery in women. Given the high prevalence of thyroid disorders in women on one hand and the hormonal changes and multiple metabolic needs occurring during pregnancy affecting the mother's thyroid function on the other, it is recommended that all pregnant women check their thyroid gland function before trying for pregnancy to prevent adverse consequences of thyroid disorders.

Finally, in agreement with other previous studies [23,35-38], the results of our study indicated that there is a significant statistical association between the history of urinary tract infection and preterm delivery after adjusting the confounding variables (OR, 16.60; 95\% Cl, 3.20-85.92). A study by Shoja et al. [23] demonstrated that there was a significant statisti- 


\section{Obstetrics \& Gynecology Science}

Mehrdad Valipour, et al. Risk factors of preterm delivery

cal relationship between pregnancy infection and preterm delivery $(\mathrm{OR}, 2.78 ; 95 \% \mathrm{Cl}, 1.07-7.20)$. Another study in this field showed that mothers with a history of urinary tract infection had a 1.59-fold increased risk of preterm delivery $(\mathrm{OR}, 1.59 ; 95 \% \mathrm{Cl}, 1.14-2.21)$ [38]. Different studies indicate that microorganisms in the membranes are associated with increased prostaglandin production, which is one of the important factors associated with the prevalence of preterm labor. Prostaglandin is produced by the invasion of microorganisms, coagulase protease, and elastase and the endotoxin directly induces preterm delivery. One of the most common microorganisms is $\beta$-hemolytic streptococcus, which may be present in the natural vaginal flora in $50 \%$ of women and causes $20 \%$ of preterm labor $[38,39]$. Therefore, treatment of infections in pregnancy is one of the factors that reduce the prevalence of preterm labor and its recurrence.

One of the limitations of this study that can be noted is the retrospective nature and low sample size. Therefore, it is recommended that cohort studies be carried out in larger geographic units and with a larger sample size to determine the precise causes of preterm delivery. Additionally, some information was extracted from the mother's medical records which may not be accurately recorded and associated with information bias. Also, the last limitation of this study, which should be mentioned, is selection bias. For some of the variables, such as multiparity, unwanted pregnancy, stillbirth, $\mathrm{CHD}$, etc., there were no women in the control group, therefore, these risk factors might be have been affected by selection bias rather than by the actual risks.

In summary, the results of this study suggest that multiparity, history of gestational diabetes, thyroid dysfunction, urinary tract infection, and taking care during pregnancy have a significant statistical association with preterm delivery. The area under the ROC curve for these variables was 0.86 . Therefore, performing perinatal care and identifying pregnant mothers with the above risk factors can reduce the preterm delivery rate, and subsequently reduce the consequences of preterm delivery in the infants and the mothers.

\section{Acknowledgements}

The study was supported by the Deputy of Research of the Iran University of Medical Sciences, Tehran, Iran.

\section{Conflict of interest}

No potential conflict of interest relevant to this article was reported.

\section{Ethical approval}

The research was conducted according to the principles expressed in the Declaration of Helsinki and was approved by the Deputy of Research and Ethics Committee of the Iran University of Medical Sciences, Tehran, Iran (approval number: 25526).

\section{Patient consent}

The patients provided written informed consent for the publication and the use of their images.

\section{REFERENCES}

1. Obstetrics Subgroup, Chinese Society of Obstetrics and Gynecology, Chinese Medical Association. Diagnosis and therapy guideline of preterm birth (2014). Zhonghua Fu Chan Ke Za Zhi 2014;49:481.

2. Simmons LE, Rubens CE, Darmstadt GL, Gravett MG. Preventing preterm birth and neonatal mortality: exploring the epidemiology, causes, and interventions. Semin Perinatol 2010;34:408-15.

3. Goldenberg RL, Culhane JF, lams JD, Romero R. Epidemiology and causes of preterm birth. Lancet 2008;371:7584.

4. Hamilton BE, Martin JA, Ventura SJ. Births: preliminary data for 2006. Natl Vital Stat Rep 2007;56:1-18.

5. Slattery MM, Morrison JJ. Preterm delivery. Lancet 2002;360:1489-97.

6. Hamilton BE, Ventura SJ. Births: preliminary data for 2005. Health E-Stats [Internet]. Hyattsville (MD): Centers for Disease Control and Prevention; 2006 [cited 2007 Jul 15]. Available from: http://www.cdc.gov/nchs/products/ pubs/pubd/hestats/prelimbirths05/prelimbirths05.htm.

7. Hamilton BE, Kirmeyer SE. Trends and Variations in reproduction and intrinsic rates: United States, 1990- 


\section{Obstetrics \& Gynecology Science}

Vol. 63, No. 2, 2020

2014. Natl Vital Stat Rep 2017;66:1-14.

8. Beck S, Wojdyla D, Say L, Betran AP, Merialdi M, Requejo $\mathrm{JH}$, et al. The worldwide incidence of preterm birth: a systematic review of maternal mortality and morbidity. Bull World Health Organ 2010;88:31-8.

9. Kamali Fard M, Alizadeh R, Sehati Shafaei F. The effect of lifestyle on the rate of preterm birth. J Ardabil Univ Med Sci 2010;10:55-63.

10. Honest H, Bachmann LM, Sundaram R, Gupta JK, Kleijnen J, Khan KS. The accuracy of risk scores in predicting preterm birth--a systematic review. J Obstet Gynaecol 2004;24:343-59.

11. Selling KE, Carstensen J, Finnström O, Sydsjö G. Intergenerational effects of preterm birth and reduced intrauterine growth: a population-based study of Swedish mother-offspring pairs. BJOG 2006;113:430-40.

12. Langhoff-Roos J, Kesmodel U, Jacobsson B, Rasmussen $S$, Vogel I. Spontaneous preterm delivery in primiparous women at low risk in Denmark: population based study. BMJ 2006;332:937-9.

13. Jiang M, Mishu MM, Lu D, Yin X. A case control study of risk factors and neonatal outcomes of preterm birth. Taiwan J Obstet Gynecol 2018;57:814-8.

14. Zhang YP, Liu XH, Gao SH, Wang JM, Gu YS, Zhang $J Y$, et al. Risk factors for preterm birth in five maternal and child health hospitals in Beijing. PLoS One 2012;7:e52780.

15. Greenland S, Mansournia MA, Altman DG. Sparse data bias: a problem hiding in plain sight. BMJ 2016;352:i1981.

16. Greenland S, Mansournia MA. Penalization, bias reduction, and default priors in logistic and related categorical and survival regressions. Stat Med 2015;34:3133-43.

17. Mohammadian S, Vakili M, Tabandeh A. Survey of related factors in prematurity birth. J Guilan Univ Med Sci 2000;9:117-22.

18. Namakin K, Sharifzadeh G, Malekizadeh AJ. To identify the risk factors in prematurity birth in Birjand, Iran: a case-control study. Iran J Edpidemiol 2011;7:1-5.

19. Heman ML, Albini M. Risk factors for spontaneous preterm birth among aboriginal and nonaboriginal women in Manitoba. J Obstet Gynecol 2000;90:43-9.

20. Lotfalizadeh M, Mohammadzadeh A, Kamandi S, Bagheri S. Incidence and risk factors of preterm birth in Imam Reza hospital-2000-2001. J North Khorasan Univ Med
Sci 2005;8:93-100.

21. Zafarghandi N, Zafarghandi AS, Torkestani F, Fallah N, Jadidi F. Prevalence of risk factors for preterm birth. J Shahed Univ 2004;12:25-9.

22. Rajaeefard A, Mohammadbeigi A, Mohammadi M, Jolaee $\mathrm{H}$, Alipour $\mathrm{H}$. Evaluation of risk factors in preterm delivery and impact of education in its prevention. Daneshvar Med 2010;17:11-8.

23. Shoja M, Shoja E, Gharaei M. Prevalence and affecting factors on preterm birth in pregnant women Referred to Bentolhoda hospital-Bojnurd. J North Khorasan Univ Med Sci 2016;7:855-63.

24. Jakobsson M, Gissler M, Sainio S, Paavonen J, Tapper AM. Preterm delivery after surgical treatment for cervical intraepithelial neoplasia. Obstet Gynecol 2007;109:30913.

25. Hedderson MM, Ferrara A, Sacks DA. Gestational diabetes mellitus and lesser degrees of pregnancy hyperglycemia: association with increased risk of spontaneous preterm birth. Obstet Gynecol 2003;102:850-6.

26. Derakhshi B, Esmailnasab N, Ghaderi E, Hemmatpour S. Risk factor of preterm labor in the west of Iran: a casecontrol study. Iran J Public Health 2014;43:499-506.

27. Nabavizadeh SH, Malekzadeh M, Mousavizadeh A, Shirazi HR, Ghaffari P, Karshenas N, et al. Retrospective study of factors related to preterm labor in Yasuj, Iran. Int J Gen Med 2012;5:1013-7.

28. Magee MS, Walden CE, Benedetti TJ, Knopp RH. Influence of diagnostic criteria on the incidence of gestational diabetes and perinatal morbidity. JAMA 1993;269:609-15.

29. Tallarigo L, Giampietro O, Penno G, Miccoli R, Gregori $G$, Navalesi R. Relation of glucose tolerance to complications of pregnancy in nondiabetic women. N Engl J Med 1986;315:989-92.

30. Stagnaro-Green A. Maternal thyroid disease and preterm delivery. J Clin Endocrinol Metab 2009;94:21-5.

31. Casey BM, Dashe JS, Wells CE, Mclntire DD, Byrd W, Leveno KJ, et al. Subclinical hypothyroidism and pregnancy outcomes. Obstet Gynecol 2005;105:239-45.

32. Nazarpour S, Ramezani Tehrani F, Simbar M, Azizi F. Thyroid dysfunction and pregnancy outcomes. Iran J Reprod Med 2015;13:387-96.

33. Idris I, Srinivasan R, Simm A, Page RC. Maternal hypothyroidism in early and late gestation: effects on 


\section{Obstetrics \& Gynecology Science}

Mehrdad Valipour, et al. Risk factors of preterm delivery

neonatal and obstetric outcome. Clin Endocrinol (Oxf) 2005;63:560-5.

34. Blazer S, Moreh-Waterman Y, Miller-Lotan R, Tamir A, Hochberg Z. Maternal hypothyroidism may affect fetal growth and neonatal thyroid function. Obstet Gynecol 2003;102:232-41.

35. Romero R, Espinoza J, Kusanovic JP, Gotsch F, Hassan S, Erez $\mathrm{O}$, et al. The preterm parturition syndrome. BJOG 2006;113 Suppl 3:17-42.

36. Goldenberg RL, Hauth JC, Andrews WW. Intrauterine infection and preterm delivery. N Engl J Med
2000;342:1500-7.

37. Srinivas SK, Ma Y, Sammel MD, Chou D, McGrath C, Parry $S$, et al. Placental inflammation and viral infection are implicated in second trimester pregnancy loss. Am J Obstet Gynecol 2006;195:797-802.

38. Yadani S, Bouzari Z, Akhondi S. The comparison of the risk factors in the term and preterm delivery. J Babol Univ Med Sci 2015;17:7-12.

39. Valadan M, Kaveh M, Bagherzadeh S, Hasanzade M. Risk factors for recurrent preterm delivery in three university hospitals. Tehran Univ Med J 2008;65:24-9. 